Peter McLaughlin

On Having a Function and Having a Good

\begin{abstract}
One result of recent discussions on the notion of function is that the appeal to the function of something in order to explain why it is there and what it is, presupposes (willingly or not) that some system particularly relevant to the function bearer has a good. Some recent analyses of what it means to have a good trace having a good back to having a function. Two such attempts are examined and compared to a more traditional analysis. An anachronistic version of Aristotle, involving the self-production of the beneficiary, is recommended as a better starting point for a naturalistic reconstruction of the subject of benefit.
\end{abstract}

\title{
1. Means and Ends
}

Anything that plays a causal role in the workings of a larger system may be said to have a function in that system. Functions in this sense are merely effects considered from a certain perspective. If however we appeal to these effects in order to explain the presence or nature of the function bearer, we are using "function" in a different sense. If we say that the function of the valves in the veins is to constrain the blood to flow towards the heart, we may simply mean that this is what they do, that this is their contribution to the system of blood circulation. Or we may mean that this is what they do that explains why they are there. In the latter case, we will normally also imply that the valves are there because performing their function is good for the organism. This explanatory sense of function is metaphysically much more problematical than the other more descriptive sense, since it appears to involve both some sort of final causation and also the notion of having a good, of someone's being able to benefit from the performance of the function. The relation of the explanatory use of functions to final causality has been dealt with extensively in recent literature. ${ }^{1}$ It is the second problematic aspect of functions that I want to take up here: To ascribe a function to something (in the explanatory sense just mentioned) seems to presuppose that the system of which it is a part or to which it has some special connection can be said to have a good. Thus a satisfactory analysis of function needs to explicate the notion of good.

The notion of having a good has generally been discussed within the context of moral philosophy. It has been the hope of moral philosophers at least since Aristotle that the notion of good as applied to actions that we think ought to be done and to people that we think ought to be admired might be reducible

${ }^{1}$ See especially Bedau 1992a and 1992b. For surveys see Melander 1997, Nissen 1997, and McLaughlin 2001. 
to the more easily handled notion of instrumentally good for. In such a case the goodness of a good action or a good man could be understood analogously to the goodness of a good pruning knife. Unfortunately, such approaches tend to have the consequence that, just as a very bad pruning knife is not really a knife at all, so too a very bad action or person would also not really be an action or person-a consequence that Kant, for instance, seems to have embraced. ${ }^{2}$ I want however to keep the question of what it means to have a good in the first place separate from its possible ethical consequences. I shall confine the scope of my analysis to a project in descriptive metaphysics that takes account of what we presuppose when we attribute a good to something. The answer to this question may well have relevance for moral philosophy inasmuch as many moral philosophers might want to say that ceteris paribus needs and interests ought if possible to be taken into consideration. But I want to avoid the problems caused by a premature introduction of the ethical consequences into the analysis of the notion of a good and to examine it from a purely instrumental perspective. ${ }^{3}$ And in particular we should be alert to the danger that if we end up explaining the good in terms of instrumental function we have entered into a vicious circle.

There are things about which it makes sense to say that they have a good, that they have a welfare, perhaps that they have needs and an interest in having those needs satisfied. They may fare better or worse. Things can be good or bad for them. If an entity can do well or poorly, it has a good. To have a good means to be a beneficiary, to be able to be the recipient of some sorts of utility. We say that fresh air is good for children. An oil slick is bad for sea birds. Rain in July is good for the crops. Mass unemployment is bad for the country. We even say that regular lubrication is good for the lawnmower and rust harms the car. But we also say that oil is good for the smooth running of the motor; a rope is good for climbing trees; a horse is good for riding; a can opener is good for opening cans. The relation 'good for' seems to come in two forms: Something can be good for some activity or something can be good for some thing. We can distinguish fairly easily between the two questions: "What is that good for?" and "Whom is that good for?"

Aristotle seems to have seen just this kind of distinction between two different aspects of the use of the Greek preposition heneka (for the sake of). $X$ can be for the sake of doing $Y$, which in turn is (good) for some beneficiary $S$. In $D e$ anima he sent the following telegram to posterity: "That for the sake of which is twofold-the purpose for which and the beneficiary for whom." 4

The two kinds of 'good for' are related. We can ask: What is the hammer

\footnotetext{
${ }^{2}$ For Kant (at least as I understand him) only moral acts are genuinely free, and thus an evil deed is not a free action but merely causally determined behavior, and an evil person is basically not a free agent.

3 Good examples of such a premature consideration of the consequences are Hare 1989 and Feinberg 1974. Hare (244) writes: "The bicycle too has a good; one can harm it by knocking it over. But that does not entail that the bicycle has interests of the sort that could generate moral rights or duties."

${ }^{4} 415 \mathrm{~b} 2$. This distinction is attributed to Aristotle by almost every English translation of $D e$ anima (I follow Hamlyn here-German translations are not so definite), but it is nonetheless a retrospective interpretation. Since heneka can only take a genitive, what Aristotle actually says ("to d'hou heneka ditton, to men hou, to de hô") must mean something like: "But that
} 
good for?-For pounding nails into the wall. What are nails in the wall good for?-For hanging pictures. What are pictures good for? ... We could pursue such an instrumental regress indefinitely, but we normally do not. At some point we put a stop to the questioning by saying something like: "I prefer a room with pictures to one without." Pictures are good for me. What am I good for?-For me. The regress goes no farther; we just change the subject. The last link in the instrumental chain names not an activity or an instrument that is a means to some end, but rather a thing that has a good and thus seems to $b e$ an end.

We can thus distinguish between an instrumental relation that can in principle be iterated indefinitely and an instrumental relation that can stop this regress. When we say $X$ is good for doing $Y$, or $X$ is a means to $Y$, or $S$ needs/wants $X$ in order to do $Y$, etc., it is quite possible that $Y$ in turn is a means to $Z$, and $Z$ a means to something else, etc. This sort of relation is used as a narrative technique in children's stories: The old farmer Peterssen uses a fishing rod to get the key out of the cistern; he needs the key to open the shed, to get the tools, to fix the bicycle, to ride to town, to buy flour, to bake a birthday cake for his cat Findus. The means-end relation can be iterated at will. The cause of an effect can be viewed as a means to an end, and to the extent that the effect is desired the appropriate means will be desired as well. These means will become ends-but only relative ends, namely relative to the end-character of that end to which they are means. Kant called this kind of relation relative purposiveness.

Nonetheless, every chain of relative ends stops someplace with a different kind of means-end relation; it comes to an end with some beneficiary. The birthday cake baked by old Peterssen was good for the cat Findus, and that stops the regress. Relative purposiveness, says Kant, "points hypothetically" to a different kind of purposiveness. ${ }^{5}$ This second kind of purposiveness, called by Kant intrinsic or absolute purposiveness, cannot be iterated. It denotes a relation to something whose good is not merely relative to its contribution to something else. It can stop the regress of means to ends. Only something that has a good can dependably stop a regress.

Two clarifications are in order here. First, the fact that the instrumental chain ends in a different kind of relation doesn't affect the internal causal structure of the links. A screw driver is good for fixing bicycles; this is not because bicycles are good for riding to town, but because the screw driver has certain causal properties. The instrumental relation itself is objective, even though such functional categories as screw driver and bicycle are of course agent dependent. An inanimate object is not for turning screws or for riding to town independent of intentional agents, even if the properties that make it good for doing this are independent of agents. Without agents there are no screw drivers, bicycles or other artifacts - even if it is conceivable that there might be objects that have all the relevant causal properties without agents, that is, objects that would be good

for the sake of which is twofold, that [for the sake] of which and that [for the sake of which] for whom."

${ }^{5}$ Critique of the Power of Judgment $\S 63$, "hypothetisch auf Naturzwecke Anzeige gibt" (Ak 5, 369). 
for turning screws or for riding to town if they only got the chance. The cause of any effect that we decide to view from a functional perspective may be said to be good for producing that effect. But if we are certain that no intentional agent is involved in any way in the creation or use of an inanimate object, we do not give it a functional name since it is not there because it is good for what it does-unless we choose to appropriate it for this purpose. Secondly, something that has a good of its own can nonetheless also be viewed instrumentally. Just because an entity stops one particular instrumental regress, doesn't mean it cannot also be a mere link in the chain of another regress. The fact that oats are good for horses, not just for the owners of the horses, does not prevent horses from being good for riding and thus being useful to their owners.

In the following I shall examine a standard contemporary analysis of having a good, which attempts to explain having a good in terms of being alive, and then I shall examine two more recent approaches, which attempt to base having a good on performing a function. I shall then take up some of the strengths and weaknesses of the Aristotelian prototype of such arguments.

\section{Von Wright on Having a Good}

The best place to start an investigation of the notion of having a good is the systematic analysis of the notion of good in The Varieties of Goodness by Georg Henryk von Wright. In an analysis of what he calls "utilitarian goodness" von Wright takes up the Aristotelian distinction between being instrumentally good for something and having a good of one's own attempting to explain why certain kinds of thing are said to have a good:

"A being, of whose good it is meaningful to talk, is one who can meaningfully be said to be well or ill, to thrive, to flourish, be happy or miserable. These things, no doubt, are sometimes said of artefacts and inanimate objects too-particularly when we feel a strong attachment to them. ... But this is clearly a metaphorical way of speaking.

The attributes which go along with meaningful use of the phrase 'the good of $X$ ', may be called biological in a broad sense. ... What I mean by calling the terms 'biological' is that they are used as attributes of beings, of whom it is meaningful to say they have a life. The question 'What kinds or species of things have a good?' is therefore broadly identical to the question 'What kinds or species of being have a life?' ...

But what shall we say of social units such as the family, the nation, the state? Have they got a life 'literally' or 'metaphorically' only? ... I doubt whether there is any other way of answering them except by pointing out existing analogies of language. ... What is arguable, however, is whether the life and a fortiori also the good (welfare) of a social unit is not somehow 'logically reducible' to the life and there- 
fore the good of the beings-men or animals, who are its members." (von Wright 1963, 50-51)

This analysis consists basically of a definition and three assertions:

Def.: Whatever and only whatever can thrive or flourish has a good.

(1) Artifacts have a good only metaphorically.

(2) Living things can thrive or flourish. Only what lives has a good.

(3) Societies may have a good (it is hard to say whether they are really 'alive') but their good is probably reducible to the good of the living creatures that compose them.

Now, the phenomenology of von Wright's results may seem fairly plausible (and I think he is on the right track), but there is little argument to back it up. Neither (1) nor (2) is self-evident: (1) has been disputed (wrongly, I think) by a number of prominent contemporary philosophers, some of whom I shall deal with below. And it would also seem that some reservations are called for about (2): Although living creatures are surely the paradigm of things that thrive, it is not evident that they are alone in having a good, nor that being alive is what makes them have a good. And of course (3) is even formulated as a problem. However, von Wright does seem to have staked out the ground for discussion and named all the serious candidates for having a good: artifacts, organisms, and societies. These are the kinds of things that might appropriately be taken up and considered as possible beneficiaries of other things or activities. These are also the kinds of things dealt with in discussions of function and functional explanation.

Nonetheless, von Wright's analysis presupposes, with Aristotle, that to flourish or to have a good basically means to lead the good life of whatever kind of thing the thing is. It is tautologically true that only what lives can live well, but that is no argument as to why living things and only living things have a good; it may be possible to have a good without having a good life. Even if organisms are the paradigm, the question to be asked from this perspective is: What is it about organisms that makes them appropriate subjects of benefit, and do other entities have this property? Being alive does not make organisms beneficiaries; it only makes them organisms.

\section{Regan on the Good of Artifacts}

The results of von Wright's analysis of varieties of goodness pose difficulties for the moral philosopher insofar as they seem to open up the perspective that all organisms might have a good and thus that the interests not only of animals but also of plants might ground some sort of claim to moral considerability (see Goodpaster 1978). To avoid having to ascribe moral considerability to plants (and lower animals) some philosophers have assimilated them to artifacts. It 
is argued that, although plants (and lower animals) do indeed have a genuine good of their own, and thus have interests, nonetheless artifacts have interests of the same kind and thus that merely having interests is not sufficient to ground claims to moral consideration. Only interests of a certain kind are relevant to moral considerability.

Tom Regan introduces a phenomenologically plausible and argumentatively cogent distinction between "welfare interests" and "preference interests", between having an interest in something and taking an interest in something (Regan 1976, 492-94). Plants (and perhaps lower animals) may indeed have interests and be beneficiaries, but only organisms with certain cognitive powers can also take an interest in their own welfare. The lower form of interests is then declared to be morally inconsequential because artifacts, too, possess such interests, and no one ascribes them any claims to moral considerability. For our concerns it is only the argument for the proposition that artifacts can be beneficiaries that is of interest, not the original motives for adducing it (Regan 1976; 1983; Frey 1980, 78-82).

Regan argues basically along the following lines: Whatever can be better or worse of its kind is said to have a good. If, for instance, a car can be a good car or a less good car, then there must be something that makes it better or worse. Whatever makes a car a good car benefits it; whatever makes it a worse car harms it. An entity has an interest in acquiring those things that benefit it and in avoiding those that harm it. Oil is not just good for the smooth running of the motor, it is good for the motor itself. And rust is bad for it. These are objective relations that are independent of any value judgment about transportation. We value a particular kind of car because it is a good car, it is not a good car just because we value it. Even if cars go out of style and roads disappear, still a good car remains a good car as long as it remains a car in good condition. An artifact has a function or characteristic activity for which it was designed and which defines what it is (Aristotle called this its ergon). Whatever supports this characteristic activity or function contributes to the kind of good that the artifact can have. The fact that the artifact can also have an instrumental value for its owner no more deprives it of a good of its own than does the instrumental value of barnyard animals and agricultural plants deprive them of a good of their own.

However, the examples of this kind adduced by Regan and others and the arguments that they support are problematical since they derive their intuitive plausibility from a misunderstanding about the objectivity of means-ends relations and from unspoken contingent presuppositions about the 'goodness' of an artifact's function.

Although the causal properties that make a thing a good token of its type are objective and independent of our evaluations of the desirability of the type, it is we who decide what functional type an individual entity instantiates. Functional categories are independent of this or that person's whims or considered judgments, but they are not independent of social context as such. The quality of a particular hunting rifle is independent of whether we approve of hunting, of whether we have hunting as an end, but it is not independent of the institution 
or practice of hunting. Regan argues that a good car remains a good car even if transported to a far planet where no one values or knows about transportation. But that is not the point. If its physical properties and physical context do not change, a good car will indeed remain good as long as it remains a car at all. This is the point: whether it is still a car. The natural and social environment can change in such a way that we would say it used to be a transportation device but it has now lost this function. What is it that makes an individual inanimate object a token of a functional type? Functional categories are agent relative and socially determined; without some relation to some subject there are no artifacts and no corresponding functional categories. If an artifact-like thing arises by accident in the wilderness- - e.g., the spontaneous generation of a lawn mower-it would not have a function, it would not be a lawn mower, unless found by someone. And if the spontaneous generation were not entirely successful, it wouldn't be a malfunctioning lawn mower, either. Where no intentionality is involved, there are no artifacts, no artifactual functions, and no corresponding functional categories. ${ }^{6}$ There are physical reasons why complex organisms cannot be spontaneously generated on an uninhabited planet; but there are conceptual reasons why artifacts cannot be so generated. There is no point in appealing to naive linguistic intuitions here, since these would merely be based on the assumption that someone had actually designed the lawn mower (vestigium hominis video). But even a real original design does not give something a function forever. Roman coins are not means of circulation any more; they had this function once but no more. We may call them coins but not money; they are no longer for purchasing commodities, even if that is what they were designed for.

Regan's argument for the good of artifacts draws its initial plausibility from a purely contingent feature of the example he uses: Although oil is indeed instrumentally good for the smooth running of the motor, it is also at the same time instrumentally good for the preservation of the motor. If something is good for both the performance of the function and for the preservation of the function bearer as a potential performer of that function, we are very easily disposed to say that it is good for the thing itself. Von Wright noted "that which is good for the car or watch is something which will keep it fit or in good order with a view to its serving a purpose well" (von Wright 1963, 50), but he insisted that "good for" is meant only metaphorically. Good for the motor means good for the preservation and performance of the motor. We can and must of course go on and ask for what or for whom the performance and preservation the motor is good. Motors don't stop an instrumental regress on their own. It is completely contingent, whether what supports the function of an artifact also supports the preservation of that artifact. For instance, a detonator is necessary for the performance of the function of a torpedo, but we would hardly want to say that it is good for the torpedo; it's good for blowing up ships. The torpedo is not benefited even metaphorically by fulfilling its function, exploding. Nor does a lollipop flourish by being licked into oblivion. If we wanted to talk about the 'good' of torpedoes, we might even prefer to say that it is better for the torpedo to miss the ship or to have a faulty detonator, so that it can survive to tell sea-

\footnotetext{
${ }^{6}$ On this particular point Searle 1995 is unquestionably right.
} 
faring tales to its grandchildren. But the point is not that only those artifacts whose characteristic activity happens to be compatible with their survival have a good; rather it is that the contingent nature of the connection between function and survival seems to prevent their having the kind of good we freely ascribe to organisms.

This may be easier to see if we take the example of an organic artifact: a sheep dog, a boundary hedge, or a kefir culture. Assume for the moment that artifacts do have a good as Regan supposed. A sheep dog has a characteristic activity, e.g., to guard sheep; and what is good for the performance of this function is good for the sheep dog. But we can perfectly well distinguish between what is good for the sheep dog qua sheep dog and what is good for it qua dog. For instance, leg of lamb is good for the dog, although eating lamb clearly contradicts the function of the sheep dog. And if we send such an entity to a far planet or let it arise there spontaneously, it is a dog from the start but it only becomes a sheep dog when we arrive. It is the sheep dog that has a function or an instrumental good for the shepherd, and it is the dog that has a good of its own. ${ }^{7}$ Thus Regan's attempt to explicate the notion of having a good in terms of instrumental functionality does not lead us into the vicious circle of basing function on the good and the good on function-because it fails.

\section{Thomson on the Good of Artifacts}

Judith Jarvis Thomson goes a step farther than Regan in championing the good of artifacts, which she takes to be paradigmatic of the goodness relation she wants to take as the basis of ethics. Whereas Regan seemed at least to allow a naturalistic foundational argument that having an interest is basic and taking an interest is higher and emergent, Thomson derives the former from the latter. She then starts with the purported good of artifacts and works up through the good of organisms to the good of 'people'. First she distinguishes three first order ways of being good: Something may be aesthetically, performatively, or instrumentally good. Something may be (more or less) good to look at or listen to or perhaps be rid of. Someone may be good at playing chess or stacking empty beer cans. Something may be good for baking cheese cake or poisoning wells. But she also introduces a fourth first-order way of being good, "namely, being good for a thing" (Thomson 1997, 290), which is involved in or presupposed by the others. This fourth way of being good is obviously somehow related to the instrumental good, but it is supposed to have some crucial properties that can make it the basis of morals.

Taking a cue from discussions of function and functional explanation in the philosophy of science, Thomson tries to define having a good in terms of having a "design function". Philosophy of science commonly distinguishes among design functions, use functions, and service functions (see Achinstein 1977). A thing $Y$ may be designed (created or appropriated) to do $A$, it may (afterwards) regularly be used to do $B$, and it may serve as $C$ on a particular occasion.

\footnotetext{
7 The source of the sheepdog example is Wilkes 1978.
} 
A lead pipe may be designed for conducting fluids, habitually be used as a blunt instrument, and serve on occasion as ballast. In design functions intentionality is involved in the origin or production of the function bearer. In use functions intentionality need only be involved in the preservation or application of the function bearer. In service functions intentionality need play no relevant role at all. Thomson takes use functions to come and go with context, whereas design is indelible; apparently the will of the original agent involved in the production of the function bearer is permanent: an artifact retains its design function come what may. And to a certain extent this is true inasmuch as an artifact normally retains its function independent of the later history of its manufacturer. Thomson wants to argue that to have a good it is sufficient to have a design function, and that whatever supports the performance of that design function (in the right way) is good for the function bearer in question. To have a good is to have a design function that can be supported by external or internal objects.

According to Thomson an artifact $Y$ has a function $A$ iff it is designed to do $A$. And since an entity may be designed to do various things, it may thus have various design functions. It is a design function of a watch to tell the time just in case telling the time is one of the things the watch was designed to do. And a thing $X$ can be said to be 'good' for an artifact $Y$ iff it conduces to $Y$ 's performing its function $A{ }^{8}$ Thus regular oiling is good for a lawn mower if it supports the lawn mower's design function of mowing lawns. Thomson gets no farther than Regan in championing the good of artifacts; her artifacts can no more stop a functional regress on their own than can Regan's.

Thomson's notion of design function as anything the function bearer is 'designed to do' diverges significantly from the concept of function in philosophy of science to which she originally appealed. To take some simple examples: A watch is designed to tell the time, and telling time is indeed the function of the watch. However, the watch may also be designed to resist water and to last a lifetime; nonetheless it is not the function of a watch to resist water nor to last a lifetime. There is something strange about asserting that this particular watch is for telling the time, for resisting water and for lasting a lifetime. It may indeed be characteristic of watches of a certain kind that they resist water or last a lifetime, but to speak of functions in this context is quite idiosyncratic. ${ }^{9}$

Following a fairly widespread (though by no means unobjectionable) practice of speaking of 'design' in nature, ${ }^{10}$ Thomson, in a second step, takes organisms to

\footnotetext{
8 The actual definition reads "if $Y$ is an artifact, then (i) $X$ is good for $Y$ just in case $X$ benefits $Y$ and (ii) $X$ benefits $Y$ by and only by conducing to $Y$ 's doing what it is among $Y$ 's design functions to do" (Thomson 1997, 291; emphasis added). The redundancy of the definition may be an attempt to avoid such problems as the good of the torpedo. But Thomson has made no preparations whatsoever to make it intelligible how something can benefit $Y$ without also being good for $Y$; and thus it is hard to see how the two can fail to covary.

${ }^{9}$ What we really mean in such a case is that the casing of the watch has the function of making the watch water resistant or that the materials are so selected that the watch may last a lifetime. We should distinguish here between the functions of parts or features and the function of wholes; and not every design ascription justifies a function ascription on the same level.

10 This metaphorical way of speaking has been vigorously and rightly criticized by Fodor
} 
perfluous for Thomson's argument about persons. It is true that organisms have always been the paradigm of things that have a good, and it would probably be a pity if they simply fell outside the scope of a given analysis of having a good. But if that's the way things are, so be it. However, if persons were not also organisms, what reason would we have to ascribe them a good in the first place? No argument independent of the unsuccessful one for the 'good' of artifacts is given that persons have a good at all. Persons are said to be able to design or produce themselves, but Thomson is explicit (297) that being designed is not what gives a person a good. If it has been clearly established that persons have a good, then it may be plausible to assert that something that is instrumentally good for accomplishing a person's projects is good for that person. However, since all real people are organisms (human beings), the simple fact that they all do have a good tells us nothing about whether their personhood is in any way relevant. Thomson's notion of a person's good, as we have seen, is not anchored naturalistically in an organic good but idealistically in the will and representation of an agent. And for an agent to accomplish her projects is only good for the agent if she has a good in the first place, just as it can only be good for a torpedo to blow itself up (or not to blow itself up) if it has a good of its own.

However unsuccessful Thomson's project may ultimately be, she seems in one respect to be looking in the right direction: It is the circumstances of the production of the entity said to have a good or a function that are definitive. The good of an artifact depends on the designs of its producer. The good of an organism is supposed to depend on the (metaphorical) designs of its as-if producer. But the good of a person or agent depends simply on his/her being able to have designs. It is unclear why the will and design of a (disembodied) agent may be said to confer a good or the ability to have a good-unless we intend to develop a philosophy of the self-production of the spirit.

\section{Aristotle's Ergon Argument}

Aristotle is notorious for a somewhat more naturalistic version of the arguments we have just examined. It would be easy, Aristotle tells us in the Nicomachean Ethics, to determine what a good man is if we only knew what the function or characteristic activity (ergon) of a man is. A good pruning knife is one that performs its function well and a good man would be one who performs his function well. Something is good for a (good) pruning knife if it supports its function and something would be good for a (good) man if it supported the performance of his function. In the Nicomachean Ethics, in the so-called ergon argument, Aristotle presents a paradigm case of pars-pro-toto fallacy (both in set-theoretical and mereological form). After remarking that a good craftsman performs his characteristic activity well and that a good organ fulfills its task well too, he poses the rhetorical question whether man himself doesn't have a task. That is, given that certain kinds of people have functions and certain 
be 'designed' by natural selection. Like artifacts, organisms too are said to have a design function. In the same way as the watch could be said to be designed to last a lifetime, so too a horse is said to be designed to survive: "every animate object $Y$ has the following design function: to survive." (Thomson 1997, 293) In attributing a function to organisms, however, Thomson definitely parts company with those philosophers of science to whom she originally appealed. Horses do not have a function, e.g., feeding the lions, in the same sense that a can opener has the function of opening cans. And while it may make metaphorical sense to say a horse is 'designed' for survival, there is not even a metaphorical sense to the assertion that a horse's function is to survive. We might just as well say that the function of a drunkard is to be inebriated. It is one of the differences between modern biologists and eighteenth century physico-theologians, that the former often ascribe functions in an explanatory sense to organs but not to organisms while the latter ascribed functions to both. In contemporary science the organs of a zebra may be said to have functions, which may (truly or falsely) be said to explain why they are there, but the zebra itself has no function that explains why it is there.

In the third step of Thomson's argument people are taken to have designs of their own: they can determine their own functions. ${ }^{11}$ But it is not asserted that natural selection has 'designed' human beings to be able to design their own projects. In fact it is not even asserted that people are the products of natural selection; they are in any case not assigned a biological design function like survival. There is nothing organic left in the functions of persons/people. Rather their good consists in fulfilling or carrying out individual projects of their own design. Good for a person means good for the pursuit of that person's designs or good for the performance of that person's self-designed functions. People may even redesign themselves - or at least the bodies attached to them-to fit their projects.

Thomson's appeal to functions actually turns out to be a superfluous detour; it is really design that counts. Artifacts are the paradigm of intentionally designed things. Organisms, on the other hand, scarcely have a function even in a metaphorical sense, in the sense that they are 'designed' by natural selection for reproductive success. Attributing functions to organisms captures neither the usage of everyday language nor of biological science. Thomson can without loss drop the function vocabulary and go straight to design. Persons or intentional agents can design artifacts for particular performances. They may also design life projects for themselves and in a sense design themselves for particular performances: playing chess, lifting weights, etc. In the case of organisms no intentionality, no will or representation is involved; and organisms are quite su-

1997. Darwin did not in fact discover "that we can think of design without a designer" (Thomson 1997, citing Kitcher 1993) any more than he discovered that we can think of artifacts without an artisan or valleys without mountains. What Darwin enabled us to do is to conceptualize adaptation without intentionality.

11 I read Thomson as using the term people not as a synonym for "human beings" nor as a gender-neutral substitute for "men" but as the plural form of the technical term person. There is no indication in the text that animals and disembodied spirits are not 'people' and some indication that they are. 
parts of people have functions, shouldn't we expect that people themselves have functions? ${ }^{12}$

"Is it really the case that carpenter and tanner have some function [ergon] and activity, but man has none but is rather born lazy? Or just as eye, hand and foot and in general each of the parts seems to have some function, in this way one might assume that man, too, has some function beside all these. But what might this be? For life seems to be common also to the plants, but the properly human is being sought. One must put aside therefore the nourishing and growing life. It might be some perceptive activity, but it seems that this is also common to horse and ox and all animals. The activepractical life of what has reason remains."

To his credit, as we can see, Aristotle does not actually answer his rhetorical question, but rather a quite different question. He asks whether man does not have an instrumental function like a craftsman for the community or an organ for the body. However, his answer states not that man is good for something or someone, but rather that, yes, man must have a good of his own; in fact he must have a good of his own above and beyond that of his vegetative and sensitive good: a rational good. The question dealt with what man is good for, but the answer deals with what kind of good man has. Aristotle has not reduced the good to external function; he has simply changed the subject. The performance of the function of the craftsman and of the organ is good for some other thing. But the performance of the characteristic activity of an organism (whether plant, animal or man) is good for the thing itself.

The ergon of a thing is what it does that makes it what it is. The pruning knife and the flute player do something that makes them what they are (i.e., gives them their names). And through the intervention of intentionality the representation of what they are supposed to do is part of the causal chain that leads to their production or training. Organisms (including plants and men) on the other hand, are said to have a good of their own inasmuch as they grow and nourish themselves. This may provide the beginnings of an explanation of how the characteristic activity can explain the production of the organism. If we give this view a somewhat anachronistic, post-Lockean interpretation, we may say that organisms produce or reproduce themselves by metabolism (growth, regeneration), and thus that they do something that makes them what they are in a much more direct way than other kinds of thing. The ergon of what vegetates is self-production. This may be what seems to give them a good of their own which can then be extended in higher beings by sensation and reason. ${ }^{13}$

In artifacts as we have seen, the performance of function and the preservation of the function bearer were only contingently connected. And the ergon of the artifact was something taken as good by someone at least in the sense that it was willed by some agent. The characteristic activity of an organism, on the other

12 Nicomachean Ethics I (7), 1097b29-1098a4. See especially Suit 1974.

13 I deal with this problem in detail in my 2001, chapters 8 and 9. 
hand, is good for an organism of that kind. The performance of the characteristic activity and the preservation of the entity are no longer contingently connected since the self-preservation and self-production of the organism is its characteristic activity. Being good for the self-production of the organism and being good for the organism itself are more than difficult to distinguish.

This does bring us a bit farther than von Wright's position. We may now have a means to say under what conditions he was right to ascribe a good to all organisms and to deny it to all artifacts (at least to those that we are familiar with). Whatever has its self-production as its characteristic activity has a good. With this we can go another step and take up von Wright's third question: Do communities, nations and other collective entities have a good of their own? We need not narrow our scope to the question of whether such entities may be said to be alive or whether we can reduce their interests to those of the individuals that compose them. Instead we can ask whether it makes sense to conceive of societies as self-producing or self-preserving systems. Not whether they are organisms, but whether, like organisms, what they do literally makes them what they are.

Thomson's extreme idealism based having a good in the last analysis on having (or depending upon) a will and a representation; she talks not about the good of a human being but about that of a person. Aristotle's man, on the other hand, has a rational soul and accordingly a specifically human activity above and beyond that of his vegetative and sensitive 'functions', but in the normal case he carries on all three activities. We can scarcely imagine Aristotle considering a life to be a paradigmatically good life in which the vegetative and animal needs were not tendentially satisfied. A starving and sensory deprived virtuoso lyre player living only to play music is not Aristotle's model of leading a good life; it is bad for the man to be undernourished and to lack perceptions - though Thomson may be right that a person's goals can be defined voluntaristically exclusively in terms of his or her life projects. And while it may seem somewhat counterintuitive to say that something is 'bad' for someone even though it is in fact necessary for one of that person's well-considered projects, nonetheless it may surely be said to be bad for the human being whose personality is so strange. And we are sure that the human being has a good, while we are only assured by Thomson that the person has one too. Any halfway rational friend of the fanatical lyre player will rightly tell him that practicing 20 hours a day is bad for him whatever his projects, and under most imaginable scenarios anyone intimate with him would be morally obliged to try to intervene. For all we know (and for all Thomson has argued), attributing a good to (disembodied) persons may be as metaphorical as attributing it to lawnmowers.

\section{Bibliography}

Achinstein, P. (1977), Function Statements, in: Philosophy of Science 44, 341-367

Aristotle (1993), De anima: books II and III (with passages from book I), transl. with introd. and notes by D. W. Hamlyn, Oxford

- (1984), The Complete Works of Aristotle, (ed. by Jonathan Barnes) Princeton 
Bedau, M. (1992a), Where's the Good in Teleology?, in: Philosophy and Phenomenological Research 52, 781-806

- (1992b), Goal-Directed Systems and the Good, in: The Monist 75, 34-51

Feinberg, J. (1974), The Rights of Animals and Unborn Generations, in: W. Blackstone (ed.), Philosophy and Environmental Crisis, Athens, 43-68

Fodor, J. (1997), Deconstructing Dennett's Darwin, in: Mind and Language 11, 246262

Frey, R. G. (1980), Interests and Rights. The Case against Animals, Oxford

Goodpaster, K. (1978), On Being Morally Considerable, in: Journal of Philosophy 75, 308-325

Hare, R. M. (1989), Moral Reasoning about the Environment, in: R. M. Hare, Essays on Political Morality, Oxford, 236-253

Kant, I. (2000), Critique of the Power of Judgment, (transl by P. Guyer and E. Matthews), Cambridge

Kitcher, P. (1993), Function and Design, in: Midwest Studies in Philosophy 18, 379397

McLaughlin, P. (2001), What Functions Explain. Functional Explanation and SelfReproducing Systems, Cambridge

Melander, P. (1997), Analyzing Functions. An Essay on a Fundamental Notion in Biology, Stockholm

Nissen, L. (1997), Teleological Language in the Life Sciences, Lanham

Regan, T. (1976), Feinberg on What Sorts of Beings Can Have Rights, in: Southern Journal of Philosophy 14, 485-498

- (1983), The Case for Animal Rights, Berkeley-Los Angeles

Searle, J. (1995), The Construction of Social Reality, New York

Suit, B. (1974), Aristotle on the Function of Man: Fallacies, Heresies and Other Entertainments, in: Canadian Journal of Philosophy 4, 23-40

Thomson, J. J. (1997), The Right and the Good, in: Journal of Philosophy 94, 273298

von Wright, G. H. (1963), The Varieties of Goodness, London

Wilkes, K. V. (1978), The Good Man and the Good for Man in Aristotle's Ethics, in: Mind 87, 553-571 